\title{
X-ray laser development at the Institute of Laser Engineering, Osaka University with worldwide collaboration
}

Yoshiaki Kato, Hiroyuki Daido

Yoshiaki Kato, Hiroyuki Daido, "X-ray laser development at the Institute of Laser Engineering, Osaka University with worldwide collaboration," Proc.

SPIE 11886, International Conference on X-Ray Lasers 2020, 118860D (8 July 2021); doi: 10.1117/12.2592812

SPIE. Event: XVII International Conference on X-Ray Lasers, 2020, Online Only 


\title{
X-ray laser development at the Institute of Laser Engineering, Osaka University - with worldwide collaboration -
}

\author{
Yoshiaki Kato*a and Hiroyuki Daido**b \\ a Institute of Laser Engineering, Osaka University, Suita, Osaka, 565-0871 Japan \\ ${ }^{\mathrm{b}}$ Institute for Laser Technology, 2-6 Yamada-oka, Suita, Osaka, 565-0871 Japan
}

\begin{abstract}
This paper presents a brief review of the x-ray laser development at the Institute of Laser Engineering, Osaka University, implemented with worldwide collaboration. The scaling of the x-ray lasing toward shorter wavelengths has been investigated in the recombination-pumped (RP) and electron-collisional-excitation (CE) pumped $\mathrm{x}$-ray lasers. Extension of the RP x-ray laser close to the water window is described. With the CE x-ray laser, intense lasing of the $J=0-1$ line at $19.6 \mathrm{~nm}$ in the neon-like Ge ion and lasing over $14.3-4.5 \mathrm{~nm}$ with the nickel-like ions are reported. Spectroscopic studies of the x-ray lasers are described, including the first observation of polarization of the $\mathrm{x}$-ray laser beam generated by amplified spontaneous emission. The perspective of the plasma-based $\mathrm{x}$-ray lasers is also presented.
\end{abstract}

Keywords: X-ray laser, recombination-pumping, collisional-excitation pumping, plasma spectroscopy, x-ray optics

\section{INTRODUCTION}

Development of the x-ray laser is a very attractive but challenging research subjects. ${ }^{1}$ Stimulated by the demonstrations of the soft x-ray lasers at Lawrence Livermore National Laboratory ${ }^{2}$ and Princeton University in 1985, we have started the x-ray laser research in 1986 using the high-power lasers developed for laser fusion research at the Institute of Laser Engineering (ILE), Osaka University. ${ }^{4}$ The recombination-pumped and the collisional-excitation-pumped x-ray lasers were investigated in close collaboration with many scientists worldwide. In this article we briefly review major outcomes of the x-ray laser development at ILE. The perspective of the plasma-based x-ray lasers are also presented.

\section{RECOMBINATION-PUMPED X-RAY LASER}

\subsection{Extension of C VI Balmer- $\alpha$ laser to shorter wavelengths}

With the objective to demonstrate $\mathrm{x}$-ray amplification in the water window region, we have started the $\mathrm{x}$-ray laser research based on the recombination-pumping scheme. A schematic diagram of the energy levels of the hydrogenic ion of an atom $\mathrm{A}$ with the atomic number $Z$ is shown in Fig. 1.

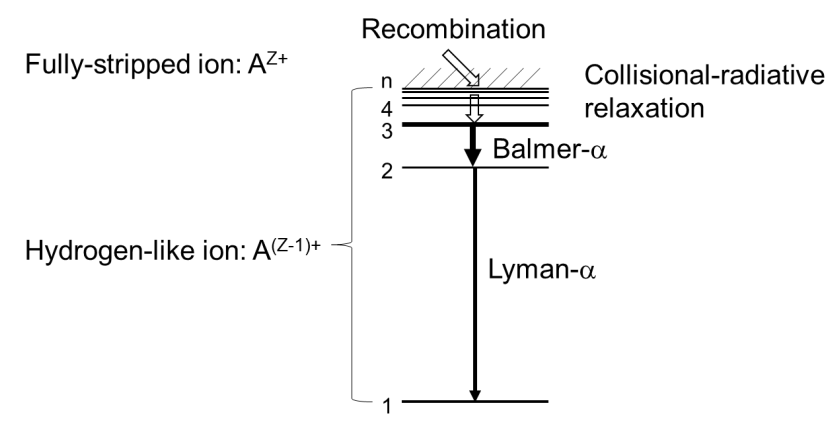

Figure 1. A simplified energy level diagram of the hydrogenic ion of an atom A with the atomic number Z. Population inversion is created between $n=3$ and $n=2$ levels due to electron recombination and collisional-radiative relaxation at low electron temperature.

*Y.K.: E-mail: nrg54872@nifty.com. **H.D.: E-mail: daido@ilt.or.jp

International Conference on X-Ray Lasers 2020, edited by Davide Bleiner,

Proc. of SPIE Vol. 11886, 118860D · C 2021 SPIE · CCC code:

0277-786X/21/\$21 - doi: $10.1117 / 12.2592812$

Proc. of SPIE Vol. 11886 118860D-1 
Fully stripped ions produced by laser irradiation recombine with the electrons to populate high energy states of the hydrogenic ions when the electron temperature decreases. At proper electron density $n_{e}$ and electron temperature $T_{e}$, the local thermal equilibrium (LTE) condition prevails in the high-energy states above the $n=3$ level. Since the electron in the $n=2$ level decays rapidly to the ground state by the Lyman- $\alpha$ emission, the population inversion is created between $\mathrm{n}=3$ and $\mathrm{n}=2$ levels, leading to amplification of the Balmer- $\alpha\left(\mathrm{H}_{\alpha}\right)$ line due to $3^{2} \mathrm{D}_{5 / 2}-2^{2} \mathrm{P}_{3 / 2}$ and $3^{2} \mathrm{D}_{3 / 2}-2^{2} \mathrm{P}_{1 / 2}$ transitions. The wavelength of $\mathrm{H}_{\alpha}$ scales with $Z$ as $\lambda$ (in nm) $=656.2 / Z^{2} ; 18.2 \mathrm{~nm}$ for C VI $(Z=6), 5.42 \mathrm{~nm}$ for Na XI $(Z=11), 4.56$ $\mathrm{nm}$ for $\mathrm{Mg}$ XII $(Z=12)$ and $3.88 \mathrm{~nm}$ (in the water window) for Al XIII $(Z=13)$. The proper high- $n_{e}$ and low- $T_{e}$ plasma is created in C VI by rapid adiabatic expansion cooling of the cylindrical plasma. ${ }^{5}$ Amplification of $\mathrm{C}$ VI $\mathrm{H}_{\alpha}$ has been demonstrated at the Central Laser Facility (CLF) of Rutherford Appleton Laboratory ${ }^{6}$ by irradiation of a 7- $\mu$ m diameter carbon fiber of a length up $9.5 \mathrm{~mm}$ with 70-ps laser pulses of $1-\mu \mathrm{m}$ wavelength with the absorbed intensity of $1.7 \times 10^{13}$ $\mathrm{W} / \mathrm{cm}^{2}$, resulting in the gain coefficient of $g=4.1 \mathrm{~cm}^{-1}$ and a single pass gain of 30 .

The similarity forms for the collisional-radiative equations for the hydrogenic ions by G. Pert lead to the following $Z$ scaling; ${ }^{5}$ the electron temperature $T_{e} \sim Z^{2}$, the electron density $n_{e} \sim Z^{7}$, the cooling time $t \sim Z^{-4}$ and the gain coefficient $g$ $\sim Z^{7.5}$. M. Key has shown that this $Z$ scaling has a limit at $Z \sim 12$ since the initial electron density cannot exceed the electron density of solid materials. ${ }^{7}$ In laser ablation due to inverse Bremsstrahlung absorption, the initial electron density scales as $n_{e} \sim Z$, although the initial electron temperature can be increased as $T_{e} \sim Z^{2}$ when the laser intensity is increased as $I \sim Z^{4}$. Starting from this initial plasma formation condition, the gain scales as $g \sim Z^{-1 / 2}$ instead of $g \sim Z^{7.5}$.

The important issue in the $\mathrm{H}_{\alpha}$ laser of high- $Z$ ions is the cooling of the electron temperature, because the expansion cooling is less effective since the electron density of the initially formed plasma is already close to the gain region. The trapping of the Lyman- $\alpha$ radiation may also be a limitation to the $\mathrm{H}_{\alpha}$ gain, ${ }^{8}$ but this issue was still unresolved. ${ }^{9}$ These analyses show that irradiation of narrow-width and possibly diluted targets by a short-duration, high-intensity, and short wavelength laser pulse is favorable for extension of the lasing to shorter wavelengths. When we apply the $Z^{4}$ dependence of the absorbed intensity to the C VI H${ }_{\alpha}$ amplification, ${ }^{6}$ the required absorbed intensity is $1.9 \times 10^{14} \mathrm{~W} / \mathrm{cm}^{2}$ for Na XI $\mathrm{H}_{\alpha}$ amplification and $3.7 \times 10^{14} \mathrm{~W} / \mathrm{cm}^{2}$ for $\mathrm{Al}$ XIII $\mathrm{H}_{\alpha}$ amplification, respectively.

\subsection{Investigation on $\mathrm{H}_{\alpha}$ amplification in Na XI, Mg XII and Al XIII with 355-nm laser pumping}

In order to investigate the $Z$-scaling of the $\mathrm{H}_{\alpha}$ amplification, we have implemented an $\mathrm{x}$-ray laser experiment using the frequency-tripled beams of the G-XII Nd:glass laser, as a joint work with the group of CLF headed by Prof. Mike Key. The experimental arrangement is shown in Fig. 2. ${ }^{10}$ Two 355-nm laser beams of 130-ps duration, each focused to a line of 30- $\mu \mathrm{m}$ width and 7-mm length with a cylindrical lens coupled with an aspheric lens, have irradiated a thin plastic film of 6-mm length coated with either $\mathrm{NaF}, \mathrm{MgF}_{2}$ or $\mathrm{Al}$ from both sides with the total intensity up to $3.3 \times 10^{14} \mathrm{~W} / \mathrm{cm}^{2}$. The spectra of the XUV emissions in the axial and transverse directions were measured with two flat-field XUV spectrometers using varied-space diffraction gratings by Hitachi. ${ }^{11}$ The spectra were recorded either with films (Kodak 101-07) for time-integrated measurement or with streak cameras (Hamamatsu with CuI and Kentech with CsI photocathodes) for time-resolved measurement. Since the gains of $\mathrm{Na}$ XI $\mathrm{H}_{\alpha}, \mathrm{Mg}$ XII $\mathrm{H}_{\alpha}$ and Al XIII $\mathrm{H}_{\alpha}$ were not high

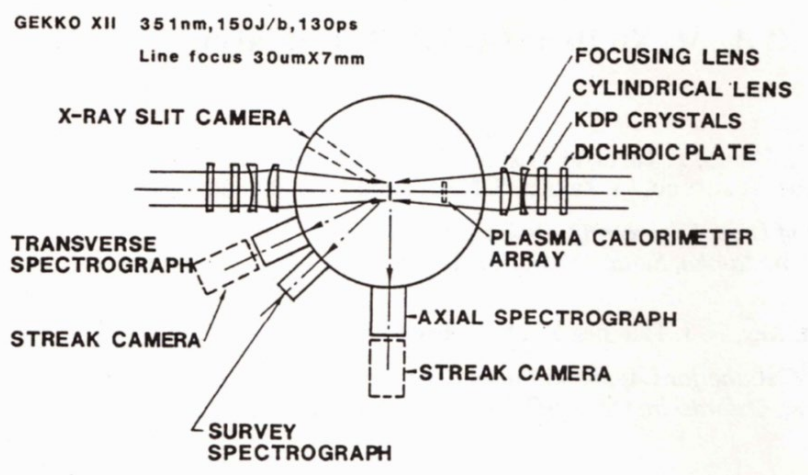

Figure 2. Layout of the x-ray laser experiment, irradiating a stripe target from both sides with two laser beams of frequency-tripled GXII laser. The XUV emissions from the target are measured with the spectrometers from the axial and transverse directions. [Ref. 10.] 


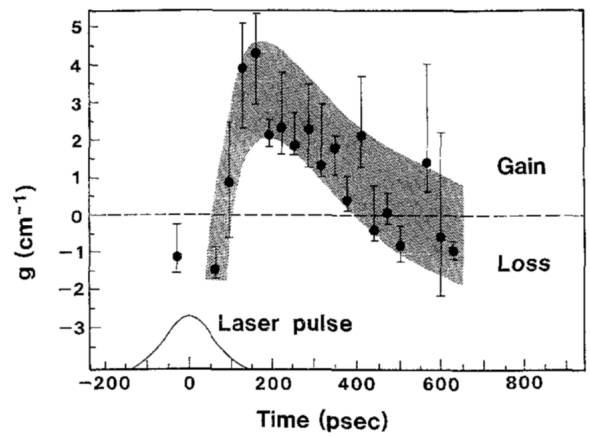

Figure 3. The experimental result of the time dependence of the gain coefficient of $\mathrm{Na} X I \mathrm{H}_{\alpha}$. [Ref. 12]

enough for gain determination from the length dependence of the line intensity, the gain or absorption of various lines were determined from the intensity ratios of the axial and transverse emissions which is given by $I_{\mathrm{a}} / I_{\mathrm{t}}=[\exp (g L)-1] /(g L)$, where $L$ is the target length, by carefully calibrating the relative sensitivity of the axial and transverse spectrometers. ${ }^{12}$

From the time integrated spectra of $\mathrm{NaF}$ and $\mathrm{MgF}_{2}$, the gain of the $\mathrm{H}_{\alpha}$ line was determined as $1.7 \pm 0.6 \mathrm{~cm}^{-1}$ for Na XI and $1.5 \pm 0.6 \mathrm{~cm}^{-1}$ for Mg XII, respectively. For the Al target, $\mathrm{Al} \mathrm{XIII} \mathrm{H}_{\alpha}$ was too weak to determine the gain, indicating that the laser intensity was not sufficient for ionization of Al to the fully stripped state. The time-dependence of gain, $g(t)$, determined from the ratio of the time-resolved axial and transverse $\mathrm{H}_{\alpha}$ intensities $I_{a}(t) / I_{t}(t)$, is shown in Fig. 3. ${ }^{12}$ The gain of $\mathrm{Na} \mathrm{XI} \mathrm{H}_{\alpha}$ at $5.42 \mathrm{~nm}$ becomes maximum with $g_{\max }=3.2 \pm 1.0 \mathrm{~cm}^{-1}$ at $\sim 200 \mathrm{ps}$ after the laser pulse. Similar gain was also observed for $\mathrm{Mg}$ XII $\mathrm{H}_{\alpha}$ at $4.56 \mathrm{~nm}$. The $\mathrm{Na}$ XI $\mathrm{H}_{\alpha}$ gain was not observed with a diluted target of $\mathrm{Na}_{2} \mathrm{~B}_{4} \mathrm{O}_{7}$, suggesting the Ly- $\alpha$ trapping may not be significant in this experimental condition.

\subsection{Increasing the gain by shorter-pulse pumping}

By applying the $Z^{-4}$ scaling of the electron cooling time to the observed value of $1 \mathrm{~ns}$ in $\mathrm{C}$ VI $\mathrm{H}_{\alpha}{ }^{6}$ the cooling time necessary for $\mathrm{Na} \mathrm{XI} \mathrm{H}_{\alpha}$ is evaluated as $\mathrm{t} \sim 90 \mathrm{ps}$. Since the laser pulse width of $130 \mathrm{ps}$ in the above experiment was too long, we have implemented another x-ray laser experiment by generating a 28-ps, 526-nm, 23-J laser pulse with one beam of G-MII laser. The laser beam was line-focused on a NaF stripe target at the intensity of $6 \times 10^{14} \mathrm{~W} / \mathrm{cm}^{2} .{ }^{13}$ The gain of $\mathrm{Na} \mathrm{XI} \mathrm{H}_{\alpha}$ determined from the time-integrated $I_{\mathrm{a}} / I_{\mathrm{t}}$ ratio was $g=4.0 \pm 1.0 \mathrm{~cm}^{-1}$, significantly higher than $1.7 \pm 0.6$ $\mathrm{cm}^{-1}$ in the 130-ps irradiation. The length dependence of the $\mathrm{H}_{\mathrm{a}}$ intensity, which we could plot in this experiment, provided the gain of $g=8.6 \mathrm{~cm}^{-1}$. The time-resolved measurement has shown that the gain becomes maximum at $\sim 50 \mathrm{ps}$ after the laser peak. The computer simulation, shown in Fig. 4, shows that the gain region appears at $\sim 60 \mathrm{ps}$ after the laser pulse at 15-20 $\mu \mathrm{m}$ away from the target surface with the peak gain of $\mathrm{g}=18 \mathrm{~cm}^{-1}{ }^{14}$ Figure 4 also shows that there is strong density gradient in the gain region, suggesting the amplified beam will be refracted. Using a curved target to compensate for the refraction, we have observed longer duration of the gain in the time-resolved measurement.

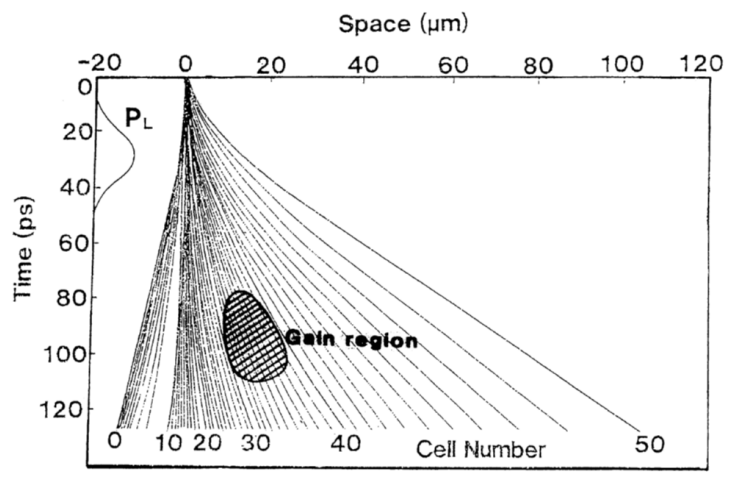

Figure 4. The plasma expansion of a NaF stripe target irradiated with a 28-ps, 526-nm laser pulse. Time runs downwards, where the laser pulse is indicated by $\mathrm{P}_{\mathrm{L}}$. The original position of the stripe is at $0 \mu \mathrm{m}$. The gain region is shown by shading. [Ref. 14] 
In order to further investigate the effectiveness of the short pulse pumping, the chirped pulse amplification (CPA) ${ }^{15}$ was introduced to the high-energy G-MII Nd:glass laser in collaboration with Dr. Chris Barty of Stanford University, generating a 1-ps, 30-TW pulse at $1.052 \mu \mathrm{m}$, the highest peak power at that time. ${ }^{16}$ Although we could not apply this laser to the x-ray laser experiment due to time constraint, this CPA G-MII laser was applied to demonstrate laser wakefield electron acceleration for the first time ${ }^{17}$ and to the fast ignition of laser fusion with the CPA G-XII laser. ${ }^{18,19}$

\subsection{Summary}

This series of investigation on the recombination $\mathrm{H}_{\alpha}$ laser has shown that the short-pulse, high-intensity, and shortwavelength laser pumping is effective in increasing the gain at short wavelengths. However saturated amplification has not been demonstrated in the $\mathrm{H}_{\alpha}$ lasers. This may be ascribed to several factors: production of the gain region uniform in space and time over a length sufficient for achieving the gain-length product of $\sim g L>10$, refraction of the x-ray laser beam due to density gradient, and possibly radiation trapping. These issues could be investigated with the high-power, short-pulse, and short-wavelength CPA lasers which are now available.

\section{COLLISIONAL-EXCITATION X-RAY LASER}

\subsection{Electron-collisional-excitation $x$-ray lasers}

In 1991 we have started to perform an experiment on the electron-collisional-excitation (CE) x-ray laser schemes of neon $(\mathrm{Ne})-$ like ${ }^{2,20,21}$ and nickel (Ni)-like isoelectronic sequences. ${ }^{22,23}$ The energy level diagrams of Ne-like and Ni-like x-ray lasers are shown in Figs. 5(a) and 5(b), respectively. Strong collisional excitation to the upper laser level and fast radiative decay from the lower laser level create the population inversion in these ions. For efficient creation of the population inversion, production of the Ne-like and Ni-like ions and creation of the energetic electrons for excitation from the ground state to the lasing states are required.

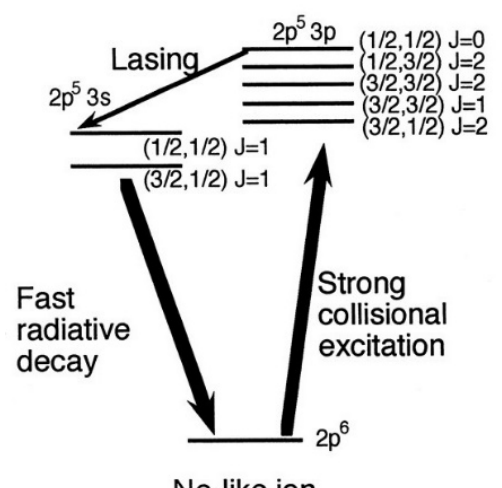

Ne-like ion

(a)

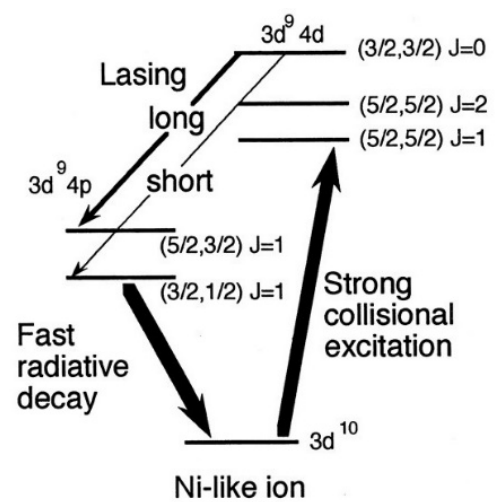

(b)

Figure 5. Simplified energy level diagrams of (a) neon-like and (b) nickel-like ions.

\subsection{Collisional-excitation $x$-ray lasers with neon-like ions}

With the neon-like ions, lasing takes place between the $2 p^{5} 3 p$ and $2 p^{5} 3 s$ states typically at the five transitions (in order of increasing the laser wavelength) : $2 p_{1 / 2} 3 p_{1 / 2}(J=0)-2 p_{1 / 2} 3 s_{1 / 2}(J=1)$ at $19.6 \mathrm{~nm}, 2 p_{3 / 2} 3 p_{3 / 2}(J=2)-2 p_{3 / 2} 3 s_{1 / 2}(J=1)$ at $23.2 \mathrm{~nm}, 2 p_{1 / 2} 3 p_{3 / 2}(J=2)-2 p_{1 / 2} 3 s_{1 / 2}(J=1)$ at $23.6 \mathrm{~nm}, 2 p_{3 / 2} 3 p_{3 / 2}(J=1)-2 p_{3 / 2} 3 s_{1 / 2}(J=1)$ at $24.7 \mathrm{~nm}$, and $2 p_{3 / 2} 3 p_{1 / 2}(J=$ $1)-2 p_{3 / 2} 3 s_{1 / 2}(J=1)$ at $28.6 \mathrm{~nm}$, where the wavelengths of the CE germanium laser are shown for each transition.

\subsubsection{Lasing properties of $J=0-1$ and $J=2-1$ lines in neon-like Ge}

On the CE x-ray laser scheme, we have started with the Ne-like $\mathrm{Ge}(Z=32),{ }^{24}$ in collaboration with the group of Queen's University Belfast (QUB), UK headed by Prof. Ciaran Lewis. Two laser beams of 1.053- $\mu \mathrm{m}$ wavelength, 1-ns pulse width and $1.1 \mathrm{~kJ}$ energy per beam was focused to a line of $6 \mathrm{~cm}$ length and $100 \mu \mathrm{m}$ average width, with an average intensity on target of $2 \times 10^{13} \mathrm{~W} / \mathrm{cm}^{2}$. Either an exploding foil (40-mm length), a single flat-slab (40-mm length) or 


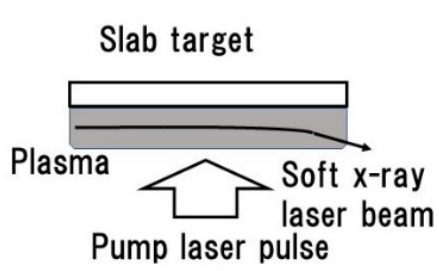

(a)

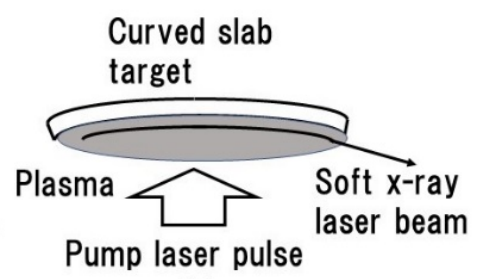

(b)

Figure 6. Schematic views of (a) single flat-slab target and (b) a single curved-slab target. The approximate trajectories of the x-ray laser beam in the plasmas of these targets are shown by the solid curves.

a double-flat-slab target ${ }^{25,26}$ was irradiated with 2 laser beams from opposite directions (see Fig. 9). The double-slab target was composed of two slab targets of half-length (26-mm length), and each slab was irradiated with a laser beam whose half aperture was blocked. Definite amplification was observed in the five lasing lines of Ne-like Ge; $19.6 \mathrm{~nm}$ due to $J=0-1$ transition, $23.2,23.6$ and $28.6 \mathrm{~nm}$ due to $J=2-1$ transitions, and $24.7 \mathrm{~nm}$ due to $J=1-1$ transition. ${ }^{27}$ It was found that the lasing property of the $J=0-1$ line was quite different from that of the $J=2-1$ and $J=1-1$ lines. The $J=0$ 1 line was amplified in the rising part of the laser pulse, and emitted at large deflection angle of $\sim 10$ mrad from the target surface with the single slab target. These results were consistent with the prediction that the $2 p^{5} 3 p(J=0)$ state, the upper level of the $J=0-1$ transition, is populated by monopole collisional excitation from $2 p^{6}(J=0)$ ground state at high electron density, whereas the upper levels of the $J=2-1$ transition are populated through relaxation from higher levels.

\subsubsection{Refraction compensation and double-pass amplification with a curved-slab target in an $x$-ray half-cavity}

In order to compensate for refraction of the x-ray laser beam due to density gradient with the slab target, which became evident in these experiments, we have tested the curved slab target originally proposed by Lunny. ${ }^{28}$ Figures $6(\mathrm{a})$ and $6(\mathrm{~b})$ show schematic views of a single flat-slab target and a single curved-slab target, respectively. With the curved slab target, the $\mathrm{x}$-ray laser beam propagates through the gain region over a long distance with a curvature which matches the refracted beam path. A Mo-Si multilayer x-ray mirror of $35 \%$ reflectivity at $23.6 \mathrm{~nm}$, fabricated at Canon Research Center, was placed at one end of the single curved-slab target, forming a half cavity for double-pass amplification in the Ge plasma. ${ }^{29}$ (Similar experimental configuration with double flat-slab targets was reported from CLF. ${ }^{30}$ ) The intensities of the $J=0-1$ and $J=2-1$ lines in single-pass amplification have increased $\sim 10$ times with the curved target compared with the flat target. When the incidence angle of the x-ray reflector was optimized in the double-pass configuration, the $J$ $=0-1$ line of less than 1-mrad divergence was stably generated, indicating the $\mathrm{x}$-ray laser beam was amplified in a plasma waveguide. ${ }^{31}$ Although the $\mathrm{x}$-ray mirror was damaged by the $\mathrm{x}$-ray laser beam, ${ }^{32}$ still the feedback by the mirror was effective at least in early time of the x-ray lasing.

\subsubsection{Multiple short-pulse pumping}

These experiments have indicated that the $J=0-1$ lasing in Ge might be enhanced if the target is irradiated with shorterduration laser pulses. Therefore, in collaboration with Prof. Chang Hee Nam of Korea Advanced Institute of Science and Technology, we have irradiated a curved slab target by two laser pulses of 100-ps duration with 300-ps separation, at the total energy of $200-300 \mathrm{~J}$ on target with various intensity ratios of the first and second pulses. With this double-pulse pumping, the $J=0-1$ line was emitted with 12 times higher peak power and reduced beam divergence compared with the 1-ns pumping, resulting in 25-times improvement in brightness. ${ }^{33}$ The intensities of the $J=0-1$ and $J=2-1$ lines have increased exponentially with the increase of the first pulse intensity, indicating that the first pulse is effective in producing a pre-plasma of proper density gradient and ionization balance for efficient excitation by the second laser pulse. The x-ray laser energy has increased further by the triple-pulse pumping. ${ }^{34}$ This multiple-pulse pumping method has enabled us to extend the lasing with the Ni-like ions to shorter wavelengths, as described in section 3.3.1.

\subsubsection{Polarization of the $x$-ray laser}

The soft x-ray laser generated by amplified spontaneous emission is generally considered unpolarized. As an attempt to generate a polarized x-ray laser beam, we have tested double-pass amplification in a Ge curved-slab target with a polarizing half cavity shown in Fig. $7 .{ }^{35}$ Between the Ge amplifier and a normal incidence multilayer reflector, we have placed a multilayer polarizer which had a polarization ratio of $R_{s} / R_{p}=120$ for the $J=0-1$ lasing line, where $R_{s}$ and $R_{p}$ are the reflectivities for the $s$ - and $p$ - polarizations, respectively. Although the total reflectivity of the polarizer and the reflector was rather small $\left(6.3 \times 10^{-3}\right.$ in double pass), we have obtained a polarized $\mathrm{x}$-ray laser beam due to double-pass 


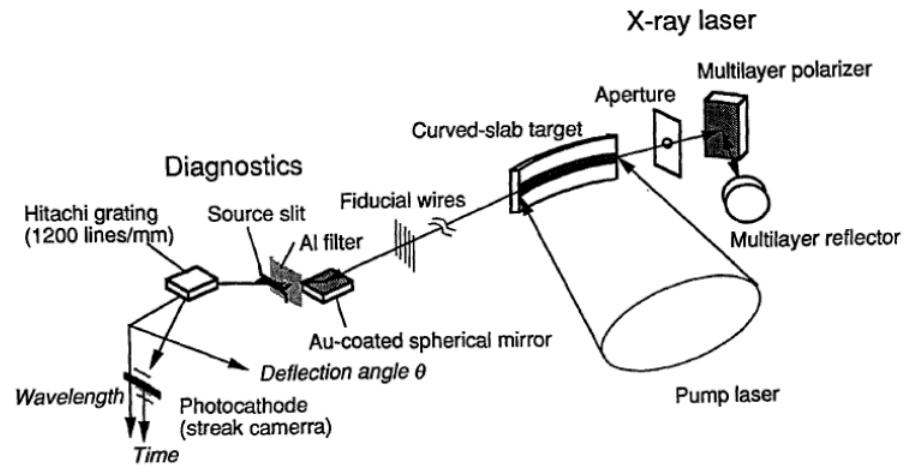

Figure 7. A polarizing half cavity with a multilayer polarizer placed in front of the reflector, and measurement of the x-ray laser beam with a flat-field grating spectrometer and a streak camera. [Ref. 35]

amplification with approximately the same intensity as the single-pass amplified beam, but with different emission time.

The soft x-ray laser beam generated by amplified spontaneous emission might be polarized if the plasma has spatial anisotropy. In collaboration with Prof. Takashi Fujimoto of Kyoto University, we have measured the polarization of the $J$ $=0-1$ line of Ge at $19.6 \mathrm{~nm}$, generated by 100-ps, double-pulse irradiation of a curved slab target. An x-ray polarizer, composed of two Mo-Si multilayer reflectors of 45-degree incidence angle with a polarization ratio of $R_{s} / R_{p}>100$ each, was placed just in front of the spectrum recording plate at the output end of a high-resolution spectrometer (described in 3.2.5), and was rotated shot-by-shot to measure the intensities of the various polarization components of the $\mathrm{x}$-ray laser beam. Denoting the coordinates $x$ and $z$ along and normal to the target surface respectively and $y$ in the observation direction as shown in Fig. 8, it was found that the x-ray laser beam was partially polarized in the $\mathrm{x}$-direction; $I_{\mathrm{x}}$ was approximately 3 times higher than $I_{\mathrm{z}}$, where $I_{\mathrm{x}}$ and $I_{\mathrm{z}}$ are the intensities of the $x$ - and $z$-polarized components of the x-ray laser beam, respectively. ${ }^{36}$ Based on quantitative evaluation of the several factors that might generate polarization anisotropy, it was concluded that the observed polarization is ascribed to the anisotropy in the trapping of the resonance line $2 p^{5} 3 s(J=1)-2 p^{6}(J=0)$. The reabsorption of the resonance line emitted toward the $z$-direction from the dipole oscillating in the $x$-direction is reduced due to the velocity gradient along $z$. This results in the population anisotropy of the lower level of the $J=0-1$ transition of $n(3 s)_{ \pm 1}<n(3 s)_{0}$ where the subscripts refer to the magnetic quantum number $M$ with $z$ taken as the quantization axis, leading to larger population inversion for the polarized lasing in the $\mathrm{x}$-direction.

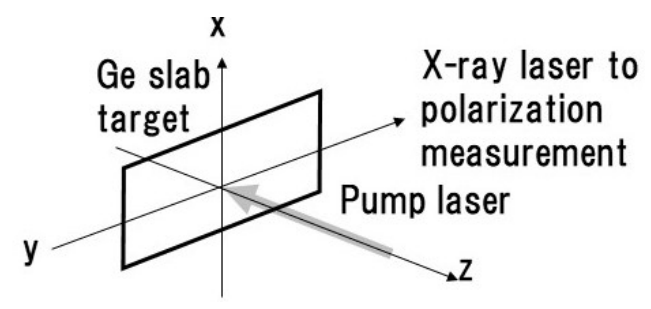

Figure 8. Configuration for polarization measurement of the x-ray laser generated in amplified spontaneous emission.

\subsubsection{Linewidth of the $x-$ ray laser}

We have measured the linewidths of the lasing lines of the Ge laser using a grazing incidence spectrometer with the resolution of $\lambda / \Delta \lambda=16,000$ (Hettrick Scientific, Model HIREFS-170.25), where a 375 lines $/ \mathrm{mm}$ unevenly spaced grating was located at $134 \mathrm{~cm}$ from an entrance slit and the focal plane was located at $409 \mathrm{~cm}$ from the grating. ${ }^{37}$ With this spectrometer, each lasing line was clearly resolved enabling determination of the linewidth of each line. The spectra were recorded with a CCD camera consisting of 1024 x 1024 array of $18-\mu \mathrm{m}$ square pixels with a dynamic range of 10,000, which was developed for x-ray astronomy by Prof. Hiroshi Tsunemi of Osaka University. ${ }^{38}$ After spectral deconvolution, the linewidths of the $J=2-1,23.2 \mathrm{~nm}$ and $23.6 \mathrm{~nm}$ lines and the $\mathrm{J}=0-1,19.6 \mathrm{~nm}$ line were determined as 
22, 21 and $25( \pm 4) \mathrm{mA}$, respectively. ${ }^{39}$ These observed linewidths are consistent with the gain-narrowed widths of the intrinsic line broadening of $\sim 50 \mathrm{~mA}$ due to Doppler broadening, collisional broadening and Stark broadening, calculated for the gain-length product of $g L=5-9$ in this experiment. More detailed understandings on the atomic physics will be obtained by further increasing the spectral resolution.

\subsubsection{In-line soft $x$-ray holography}

A preliminary experiment of the in-line Gabor holography of simple structured objects were demonstrated using the Ge soft x-ray laser as the light source, in collaboration with Prof. T. Honda of Tokyo Institute of Technology, Prof. Kunio Shinohara of Tokyo Metropolitan Institute of Medical Science, Prof. David Neely and his colleagues at QUB and King's College London. The holograms recorded on PMMA were retrieved with an atomic force microscope. The object image was reconstructed with phase retrieval algorithm, resulting in a clear, ghost-free image of sub- $\mu \mathrm{m}$ resolution, showing the potential of the x-ray laser for high-resolution 2-D and 3-D imaging. ${ }^{40}$

\subsection{Collisional-excitation $x$-ray lasers with nickel-like ions}

With the nickel-like ions, lasing takes place between the $3 d^{9} 4 d$ and $3 d^{9} 4 p$ states at the two transitions: $3 d_{3 / 2} 4 d_{3 / 2}(J=0)-$ $3 d_{5 / 2} 4 p_{3 / 2}(J=1)$ and $3 d_{3 / 2} 4 d_{3 / 2}(J=0)-3 d_{3 / 2} 4 p_{1 / 2}(J=1)$, which are called long-wavelength and short-wavelength components, respectively.

\subsubsection{Lasing in Ni-like ions at $14.3-6.37 \mathrm{~nm}$ by multiple-pulse pumping}

By applying the triple-pulse pumping technique 33,34 to the Ni-like $\mathrm{x}$-ray laser, we have succeeded in demonstrating lasing over the wavelengths of $14.3-6.37 \mathrm{~nm}$ in the following Ni-like ions; ${ }_{47} \mathrm{Ag}(\lambda=14.3 \mathrm{~nm}),{ }_{52} \mathrm{Te}(11.1 \mathrm{~nm}),{ }_{57} \mathrm{La}$ $(8.9 \mathrm{~nm}),{ }_{58} \mathrm{Ce}(8.6 \mathrm{~nm}),{ }_{60} \mathrm{Nd}(7.97 \mathrm{~nm}),{ }_{62} \mathrm{Sm}(7.32 \mathrm{~nm}),{ }_{44} \mathrm{Gd}(6.92 \mathrm{~nm}),{ }_{65} \mathrm{~Tb}(6.67 \mathrm{~nm})$, and ${ }_{66} \mathrm{Dy}(6.37 \mathrm{~nm})$, where the wavelengths of the observed lasing lines of the long wavelength component are shown in the parentheses. ${ }^{41,42}$ In these experiments, a curved slab target was irradiated with either double, triple or quadruple 1.053- $\mu \mathrm{m}$ laser pulses of 100-ps duration separated by $400 \mathrm{ps}$, with the total energy of $200-500 \mathrm{~J}$. A gain coefficient of $g \sim 3.1 \mathrm{~cm}^{-1}$ and a gain length product of $g L \sim 8$ have been achieved at $7.97 \mathrm{~nm}$ in the $\mathrm{Nd}$ ions. This multiple-pumping method has proven to be effective for reducing the laser energy required to pump these soft x-ray lasers by almost an order of magnitude. This work was later extended to the demonstration of the saturated gain in Ni-like $\mathrm{Ag}$ at $13.9 \mathrm{~nm}$ and $\mathrm{Sn}$ at $12.0 \mathrm{~nm}$ by 4-ps duration, 14-J, two-pulse pumping with a table-top laser at the JAERI Advanced Photon Research Center. ${ }^{43}$

\subsubsection{Intense lasing in Nd and Ag by quasi-travelling-wave pumping of double curved-slab target}

In collaboration with the group of National Laboratory on High Power Lasers and Physics (NLHPLP), Shanghai Institute of Optics headed by Prof. Shiji Wang, where double-target configuration has been tested in $1992,{ }^{25}$ we have irradiated two curved-slab targets by two laser pulses with a 100-ps delay for quasi-travelling-wave pumping of the two targets, as shown in Fig. 9. Double-pass amplification using a 100-layer-pair $\mathrm{Ru} / \mathrm{B}_{4} \mathrm{C}$ multilayer mirror fabricated at NTTAdvanced Technology was also implemented, where the reflected x-ray laser pulse was amplified in the plasma pumped by the next laser pulse. For target irradiation, instead of using a standard single cylindrical lens, a novel optics composed of 4 convex cylindrical lenses developed at NLHPLP was installed for uniform-width line focusing. ${ }^{44}$ A large-aperture deformable mirror was also tested for uniform line focusing, resulting in improved soft x-ray laser performance. ${ }^{45}$

With the single-pass quasi-travelling-wave amplification, we have obtained very intense lasing in the Ni-like Nd at 7.97 $\mathrm{nm}$ with $\sim 40$-ps duration and $\sim 40-\mu \mathrm{J}$ energy corresponding to $\sim 1$-MW peak power, ${ }^{46}$ and saturated amplification in $\mathrm{Ni}$ like $\mathrm{Ag}$ at $13.9 \mathrm{~nm}$ with an exceptionally high gain of $19 \mathrm{~cm}^{-1}, \sim 300-\mu \mathrm{J}$ energy and $5 \mathrm{MW}$ peak power. ${ }^{47}$ In this experiment, we found that the merit of the curved target decreased in the multiple pulse pumping scheme as discussed by Nilsen et al. ${ }^{48}$

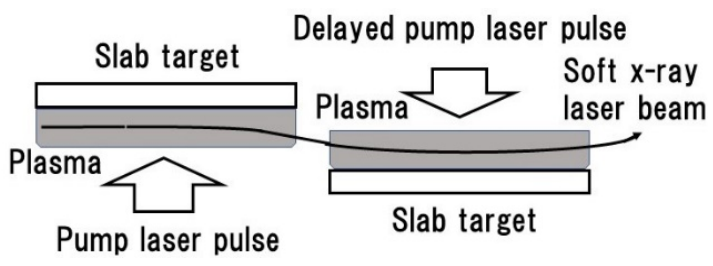

Figure 9. Quasi-travelling wave pumping of a double slab target. 


\subsubsection{Extension of lasing close to the water window}

For $\mathrm{x}$-ray lasing close to the water window with the Ni-like ions, a high density and high temperature plasma is required as an amplifying medium. For example, the desirable electron temperature and the electron density are $1-1.5 \mathrm{keV}$ and $1.5 \times 10^{21} \mathrm{~cm}^{-3}$ for $70 \mathrm{Yb}$ and $1.4-1.8 \mathrm{keV}$ and $3.5 \times 10^{21} \mathrm{~cm}^{-3}$ for ${ }_{74} \mathrm{~W}$, respectively. ${ }^{49}$ In this case, the important issue is the propagation of the $\mathrm{x}$-ray laser beam through the gain region in the plasma. ${ }^{50}$ The $\mathrm{x}$-ray propagation through the gain region is quite different at the wavelengths shorter than $10 \mathrm{~nm}$, where the obliquely incident $\mathrm{x}$-ray laser beam penetrates in the high-density non-amplifying plasma and absorbed. In this spectral region the curved target is not effective for refraction compensation, because the critical density at $10 \mathrm{~nm}$ is $\sim 1 \times 10^{25} \mathrm{~cm}^{-3}$ which is much higher than the solid density plasma.

Experiment on lasing toward the water window in the Ni-like ions was implemented in collaboration with NLHPLP and the group of Friedrich-Schiller University Jena headed by Prof. Eckart Förster. Two flat-slab targets of $8 \mathrm{~mm}$ length each was irradiated by two counter-propagating lasers of $1.053-\mu \mathrm{m}$ wavelength and 100-ps duration with a time delay for quasi-travelling wave pumping. Each laser beam was composed of a pre-pulse and a main pulse, with the main-pulse energy of $240 \mathrm{~J}$ and intensity of $3 \times 10^{14} \mathrm{~W} / \mathrm{cm}^{2}$. After extensive optimization of the target position (target separation along and vertical to the $\mathrm{x}$-ray laser beam axis) and laser parameters (delay time and pre-/main-pulse intensity ratio), the $\mathrm{x}$-ray lasing near the water window were obtained in Ni-like $\mathrm{Yb}$, Hf and Ta ions at $5.0 \mathrm{~nm}, 4.7 \mathrm{~nm}$ and $4.5 \mathrm{~nm}$, respectively as shown in Fig. 10. The gain coefficients of the Ni-like $\mathrm{Yb}$ and $\mathrm{Hf}$ lasing lines were $g=6.6 \mathrm{~cm}^{-1}$ and 3.6 $\mathrm{cm}^{-1}$ with the gain length product of $g L=11$ and 6, respectively. ${ }^{51}$ Indication of lasing in $\mathrm{W}$ at $4.3 \mathrm{~nm}$, in the water window, was also observed. According to 1-D hydrodynamic simulation for 1- $\mu \mathrm{m}$ laser irradiation, the electrons are heated to $\sim 1 \mathrm{kV}$, but the electron density of the heated region of $\sim 10^{21} \mathrm{~cm}^{-3}$ is lower than the required density.

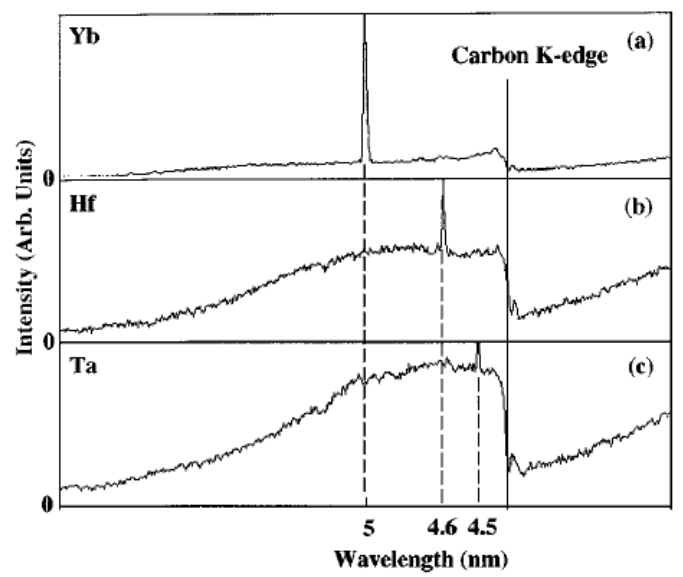

Figure 10. Observed spectra of lasing in (a) Yb, (b) Hf and (c) Ta, respectively. The carbon $K$-edge at 4.38 nm is shown as the edge of the water window. [Ref. 51]

\subsubsection{Spectroscopic study of the lasing lines in the nickel-like ions}

Although the observed intensities of the $\mathrm{Yb}, \mathrm{Hf}$ and Ta $\mathrm{x}$-ray lasers were below the saturated levels, the well-defined lasing lines are precious for spectroscopic studies. Comparing the observed wavelengths and intensities of the lasing lines in $\mathrm{Ni}$-like ${ }_{60} \mathrm{Nd},{ }_{62} \mathrm{Sm},{ }_{44} \mathrm{Gd},{ }_{6} \mathrm{Dy},{ }_{67} \mathrm{Ho},{ }_{70} \mathrm{Yb},{ }_{72} \mathrm{Hf}$, and ${ }_{73} \mathrm{Ta}$, we found that the intensity of the longer wavelength component is stronger in ${ }_{60} \mathrm{Nd} \sim{ }_{67} \mathrm{Ho}$, whereas the intensity of the shorter wavelength component becomes stronger than the longer wavelength component in ${ }_{70} \mathrm{Yb} \sim{ }_{73} \mathrm{Ta}$. Prof. Fumihiro Koike of Kitasato University has successfully clarified these experimental results of the wavelengths and line intensities, by implementing detailed relativistic atomic-physics calculation on these elements to derive the wavelengths and the oscillator strengths and also solving a simplified rate equation code to calculate the relative gain of these lines using the calculated oscillator strengths. ${ }^{52}$

Detailed account of the experiments on the development and application of the collisional-excitation soft x-ray lasers at ILE can be also found in the review papers. ${ }^{49,53-55}$ 


\section{PERSPECTIVE}

\subsection{Recombination-pumped $x$-ray laser and related schemes}

The recombination-pumped $\mathrm{x}$-ray laser has inherently high efficiency, since fully stripped ions of atoms of small atomic numbers, required in this scheme, can be generated with relatively low laser energy. Unfortunately, saturated amplification has not been demonstrated in this scheme, due possibly to several factors as described in section 2.4. Considering recent significant advances in the laser technology, it will be possible to test this scheme with more ideal conditions, i.e., travelling-wave irradiation of a target with a high-power, short-pulse and short-wavelength laser, focused to a narrow width with uniform intensity distribution.

With the high-intensity, short-duration and short wavelength lasers, it will be possible also to investigate other promising $\mathrm{x}$-ray laser schemes, such as the optical-field ionization x-ray laser ${ }^{56}$ and the resonant photo-pumping $\mathrm{x}$-ray laser. ${ }^{57}$

\subsection{Collisional excitation $x$-ray laser}

The collisional excitation soft x-ray lasers have been successfully developed over the world. The wavelengths of the typical Ne-like-ion x-ray lasers and the Ni-like-ion x-ray lasers are shown in Fig. 11 (a) and in Fig. 11 (b), respectively. Many $x$-ray applications need the $x$-ray lasers with saturated amplification, which can provide not only high intensity but also high coherence. From this point of view, useful wavelength region is restricted. Among the Ne-like soft x-ray lasers, the useful wavelength is in $~ 30-20 \mathrm{~nm}$ such as Ti, Cu, Ge, Se and Y. On the other hand, among the Ni-like soft x-ray lasers, the useful wavelength region is in $\sim 20-5.9 \mathrm{~nm}$ such as Ag, Nd, Sm and Dy. ${ }^{41}$ In the shorter wavelength regions of the Ne-like and Ni-like lasers, the intensities are far below the saturated levels. In the longer wavelength regions, the achieved intensities are far below the saturated levels. For extending the useful wavelengths both in the shorter and the longer regions, we would like to point out several issues to be considered as described below.
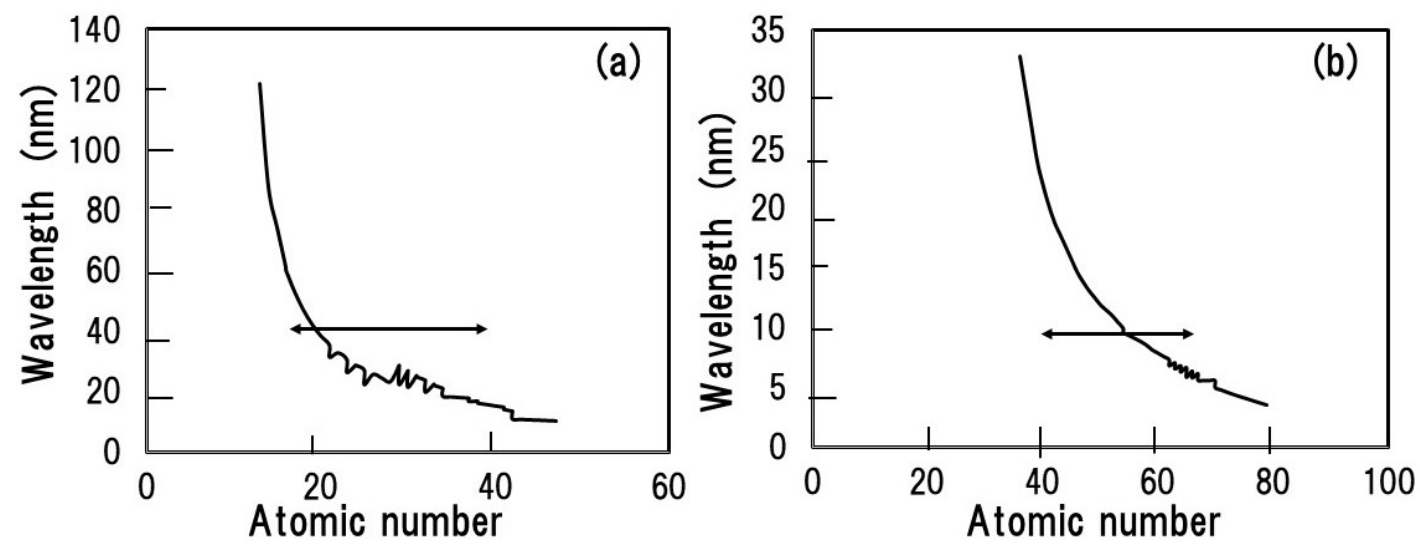

Figure 11. The lasing wavelengths of (a) Ne-like ions and (b) Ni-like ions as a function of atomic number. The horizontal bars correspond to the region of the atoms where saturated amplification has been attained.

As the requirements in the collisional-excitation x-ray laser scheme, the first requirement is that the abundance of the Ne-like or Ni-like ions should be maximized. At the same time, the abundance of the electron component which efficiently excite the ground state ions to the upper lasing levels should be maximized. For the Ni-like ions, the electron temperature for the former condition is approximately one-half to one-third of the electron temperature for the latter condition. ${ }^{53}$ This consideration leads to the separated pumping; the first laser for plasma formation and the second laser for exciting the lasing ions. Such a scheme called the transient pumping scheme, including the traveling wave pumping, was first demonstrated by P. V. Nickles. ${ }^{58}$ This scheme was successfully applied to various kinds of elements to extend the wavelength region. As the second requirement, the ray trajectory of the soft x-ray laser should continuously pass through the gain media. For this requirement, grazing incidence pumping was successfully demonstrated. ${ }^{59,60}$ This method has contributed to the reduction of the pumping laser system. However, the extension of the useful wavelength 
region is still limited. Based on these results, we would like to describe a scope for extension to shorter and longer wavelength regions.

For extension of the lasing to shorter wavelength regions such as the water window spectral region, the Ni-like ion scheme is suitable. For this purpose, it is necessary to create high density homogenous plasma which contains sufficient Ni-like ions and high energy electrons for pumping to the $4 d$ state. We propose to use multiple ultraviolet laser pulses for production of large-scale homogeneous plasma abundant with the Ni-like ions and a picosecond infrared laser pulse for production of energetic electrons for the pumping to the $4 d$ state.

On the other hand, when we see the long wavelength region, we find interesting experiments by E. Fill and his collaborators. ${ }^{61}$ Using the laser pulses with an energy of $20 \sim 50 \mathrm{~J}$ in 400 ps at $1.315-\mu \mathrm{m}$ wavelength as the main pumping source with a small prepulse, they have demonstrated Ne-like sulphur and silicon lasers with the wavelengths of $60.8 \mathrm{~nm}$ and $87.4 \mathrm{~nm}$, respectively. This spectral region is attractive for material sciences, and extension to longer wavelength region is also desirable. However, the required laser energy was rather high, although the lasing wavelength was long. According to the consideration of the scaling law by Li and Nilsen, ${ }^{62}$ one of the possible reasons is thought to be that the wavelength of the pumping laser of $\sim 1 \mu \mathrm{m}$ is too short for these ion species. We believe that the repetitive $\mathrm{CO}_{2}$ laser is one of the possible candidates. A Ne-like Al laser at the wavelength of $122 \mathrm{~nm}$, which has not yet been demonstrated, is an attractive coherent monochromatic source for VUV spectroscopy. In this spectral region we can use high quality windows to cover the specimen for irradiation.

\section{SUMMARY}

We have reviewed x-ray laser development at the Institute of Laser Engineering, Osaka University, implemented with worldwide collaboration. Extension of the recombination-pumped Balmer-alpha x-ray laser to shorter wavelengths was investigated. By irradiation of stripe targets with a $130-\mathrm{ps}, 355 \mathrm{~nm}$ laser pulse at the intensity of $3.3 \times 10^{14} \mathrm{~W} / \mathrm{cm}^{2}$, gains were observed in $\mathrm{Na} \mathrm{XI} \mathrm{H}_{\alpha}$ at $5.42 \mathrm{~nm}$ and $\mathrm{Mg} \mathrm{XII} \mathrm{H}_{\alpha}$ at $4.56 \mathrm{~nm}$, with the $\mathrm{Na} \mathrm{XI} \mathrm{H}_{\alpha}$ gain of $g_{\max }(\mathrm{t}) \sim 3.2 \mathrm{~cm}^{-1}$ attained at $\sim 200 \mathrm{ps}$ after the laser pulse. This irradiation intensity was not sufficient for ionization of Al to the fully stripped state. A higher gain in $\mathrm{Na} X \mathrm{XI} \mathrm{H}$ of $8.6 \mathrm{~cm}^{-1}$ was obtained at $50 \mathrm{ps}$ after the laser pulse, by irradiation with a 28-ps, $526 \mathrm{~nm}$ laser pulse at $6 \times 10^{14} \mathrm{~W} / \mathrm{cm}^{2}$. Based on this work, we have suggested to investigate this scheme with more ideal conditions; travelling-wave irradiation of a target with a high-power, short-pulse and short-wavelength laser, focused to a narrow width with uniform intensity distribution.

The collisional-excitation (CE) x-ray lasers in the neon-like and the nickel-like ions were investigated. With the CE Nelike x-ray laser, we have obtained the following results: efficient lasing of the $J=0-1$ line by short-pulse pumping, efficiency improvement of lasing by multiple-short-pulse pumping, refraction compensation with a curved-slab target, amplification in a plasma waveguide by operation of the x-ray laser with a half cavity, first observation of polarization of the x-ray laser beam generated as amplified spontaneous emission, measurement of the spectral width of the $\mathrm{x}$-ray laser, and preliminary experiment on the in-line x-ray holography.

Extension of the lasing to shorter wavelengths was investigated with the CE Ni-like x-ray lasers. By triple-pulse pumping, amplification was observed over the wavelengths of $14.3-6.37 \mathrm{~nm}$ in the Ni-like ions of $\mathrm{Ag}, \mathrm{Te}, \mathrm{La}, \mathrm{Ce}, \mathrm{Nd}$, $\mathrm{Sm}, \mathrm{Gd}, \mathrm{Tb}$ and Dy, with a gain-length product of $g L \sim 8$ at $7.97 \mathrm{~nm}$ in Nd. By quasi-travelling-wave pumping of double targets at high irradiation intensity, amplification in Ni-like $\mathrm{Yb}$ at $5.0 \mathrm{~nm}, \mathrm{Hf}$ at $4.7 \mathrm{~nm}$ and Ta at $4.5 \mathrm{~nm}$ were observed, with $g=6.6 \mathrm{~cm}^{-1}$ and $g L=11$ in $\mathrm{Yb}$ and $g=3.6 \mathrm{~cm}^{-1}$ and $g L=6$ in Hf, respectively.

For extension of the Ni-like laser to shorter wavelengths, we have proposed to use multiple ultraviolet laser pulses for production of a large-scale homogeneous plasma abundant with the Ni-like ions and a picosecond infrared laser pulse for production of energetic electrons for the pumping to the $4 d$ state. For extension of the Ne-like laser to longer wavelengths, we have suggested irradiation with a long wavelength laser: for example, using a $\mathrm{CO}_{2}$ laser for realization of Ne-like Al laser at $122 \mathrm{~nm}$.

Partly based on the x-ray laser research at ILE, a new R\&D program was started at Japan Atomic Energy Research Institute (JAERI) by establishing the Advanced Photon Research Center (APRC) in 1996, with Prof. Hiroshi Takuma as the Scientific Adviser, where exploration and development of new research fields with high-power ultrashort pulse lasers are pursued. After preparation period, full-scale research was started at a new research facility in Kizu, Kyoto Prefecture in $1999,{ }^{63}$ with the support of Prof. Toshiki Tajima and Prof. Gerard Mourou. This program is now actively undertaken 
at Kansai Photon Science Institute (KPSI) of National Institutes of Quantum and Radiological Science and Technology (QST) over broad fields such as high-power lasers, ${ }^{64} \mathrm{X}$-ray lasers, ${ }^{43,65} \mathrm{x}$-ray generation, ${ }^{66}$ high field science ${ }^{67}$ and particle acceleration. ${ }^{68}$ Among various approaches to generation of coherent radiation in the EUV and x-ray regions, the plasmabased x-ray lasers will have new possibilities for development by utilizing the technologies and concepts that are now available.

\section{ACKNOWLEDGEMENTS}

We would like to thank all collaborators, scientists from universities, government institutions and companies, and graduate students, who have participated in the x-ray laser development at ILE. The contributions from the international collaborators were vital in advancing these developments. The supports of the technical staffs of ILE are deeply appreciated. We would like to thank Prof. Chiyoe Yamanaka and Prof. Sadao Nakai for supporting the x-ray laser research at ILE. This work was supported partly by JSPS KAKENHI for "Research on Basic Properties of X-Ray Lasers" in 1987-1989, and by JST Special Coordinated Fund for the Promotion of Science and Technology "Generation and Application of Vacuum Ultraviolet Radiation“ in 1988-1992, organized by Prof. Susumu Namba and Prof. Koji Toyoda.

\section{REFERENCES}

[1] Waynant, R.W., and Elton, R.C., "Review of short wavelength laser research," Proc. IEEE 64, 1059-1092 (1976).

[2] Matthews, D.L., Hagelstein, P.L., Rosen, M.D., Eckart, M.J., Ceglio, N.M., Hazi, A.U., Medecki, H., MacGowan, B.J., Trebes, J.E., Whitten, B.L., Campbell, E.M., Hatcher, CW., Hawryluk, A. M., Kauffman, R.L., Pleasance, L.D., Rambach, G., Scofield, J.H., Stone, G., and Weaver, T.A., "Demonstration of a soft X-ray amplifier," Phys. Rev. Lett. 54, 110-113 (1985).

[3] Suckewer, S., Skinner, C.H., Milchberg, H., Keane, C., and Voorhees, D., "Amplification of stimulated soft x-ray emission in a confined plasma column," Phys. Rev. Lett. 54, 1753-1756 (1985).

[4] Yamanaka, C., Kato, Y., Izawa, Y., Yoshida, K., Yamanaka, T., Sasaki, T., Nakatsuka, M., Mochizuki, T., Kuroda, J., and Nakai, S., "Nd-Doped Phosphate Glass Laser Systems for Laser-Fusion Research," IEEE J. Quant. Electron. QE-17, 1639-1649 (1981); Kato, Y., Yoshida, K., Kuroda, J., and Yamanaka, C., "3.4-TW Performance of a Nd:Phosphate Glass Laser with Output Aperture of 20 cm," Appl. Phys. Lett. 38, 72-73 (1981).

[5] Pert, G.J., "Model calculations of XUV gain in rapidly expanding cylindrical plasmas," J. Phys. B 9, 3301 (1976); Pert, G.J., "Model calculations of XUV gain in rapidly expanding cylindrical plasmas. II," J. Phys. B 12, 2067 (1979).

[6] Chenais-Popovics, C., Corbett, R., Hooker, C.J., Key, M.H., Kiehn, G.P., Lewis, C.L.S., Pert, G.J., Regan, C., Rose, S.J., Sadaat, S., Smith, R., Tomie, T., and Willi, O., "Laser amplification at $18.2 \mathrm{~nm}$ in recombining plasma from a laser-heated carbon fiber," Phys. Rev. Lett. 59, 2161-2164 (1987).

[7] Key, M., "Isoelectronic scaling of plasma XUV lasers," in [Annual Report to the Laser Facility Committee, Rutherford Appleton Lab.], RAL-87-041, 100-103, 1987 (unpublished); Key, M., "A physical model of the effect of wavelength of the heating laser in isoelectronic scaling of XUV lasers operating by recombination," in [Annual Report to the Laser Facility Committee, Rutherford Appleton Lab.], RAL-89-045, 119-129, 1989 (unpublished).

[8] Eder, D.C., Rosen, M.D., Lee, R.W., Trebes, J.E., Ceglio, N.M., Eckart, M.J., Kauffman, R.L., MacGowan, B.J., and Matthews, D.L., "Effect of spontaneous emission in hydrogenic magnesium and aluminum x-ray laser schemes," J. Opt. Soc. Am. B 4, 1949-1953 (1987).

[9] Pert, G.J., and Rose, S.J., "Detailed simulation of recombination XUV laser experiments," Appl. Phys. B 50, $307-$ 311 (1990).

[10] Kato, Y., Yamanaka, M., Daido, H., Tachi, T., Nishimura, H., Shiraga, H., Miura, E., Herman, P. R., Takabe, H., Jitsuno, T., Takagi, M., Nakai, S., Yamanaka, C., Key, M.H., Tallents, G.J., and Rose, S.J., “Amplification in Na XI $\mathrm{Ha}, \mathrm{Mg}$ XII Ha and Al XIII Ha transitions," in [OSA Proceedings on Short Wavelength Coherent Radiation: Generation and Applications], R. W. Falcone and J. Kirz, eds. Vol. 2, 47-51, Optical Society of America, Washington, D. C. (1988).

[11] Harada, H. and Kita, T., "Mechanically ruled aberration-corrected concave gratings," Appl. Opt. 19, 3987-3993 (1980). 
[12] Kato, Y., Miura, E., Tachi, T., Shiraga, H., Nishimura, H., Daido, H., Yamanaka, M., Jitsuno, T., Takagi, M., Herman, P. R., Takabe, M., Nakai, S., Yamanaka, C., Key, M.H., Tallents, G.J., Rose, S.J., and Rumsby, P.T., "Observation of gain at 54.2 A on Balmer-alpha transition of hydrogenic sodium," Appl. Phys. B 50, 247-256 (1990).

[13] Azuma, H., Kato, Y., Yamakawa, K., Tachi, T., Nishio, M., Shiraga, H., Nakai, S., Ramsden, S.A., Pert, G.J., and Rose, S.J., "Short-pulse pumping of a recombination Balmer- $\alpha$ laser of hydrogenic sodium," Opt. Lett. 15, 10111013 (1990).

[14] Kato, Y., Azuma, H., Murai, K., Yamakawa, K., Shiraga, H., Pert, G.J., Ramsden., S.A., Key, M.H., and Barty, C.P.J., "Explosive-mode short wavelength recombination Balmer-a laser," in [X-Ray Lasers 1990], Tallents, G. J., ed., 1-8, IOP, Bristol (1991).

[15] Strickland, D., and Mourou, G., "Compression of amplified chirped optical pulses," Opt. Comm., 56, 219-221 (1985).

[16] Yamakawa, K., Shiraga, Y., Kato, Y., and Barty, C.P J., "Prepulse-Free 30-TW, 1-ps Nd:glass Laser,” Opt. Lett. 16, 1593-1595 (1991); Yamakawa, K., Barty, C.P.J., Shiraga, H., and Kato, Y., "Generation of a high-energy picosecond laser pulse with a high-contrast ratio by chirped-pulse amplification," IEEE J. Quant. Electron. 27, 288294 (1991).

[17] Nakajima, K., Kawakubo, T., Nakanishi, H., Ogata, A., Kato, Y., Kitagawa, Y., Kodama, R., Mima, K., Shiraga, H., Suzuki, K., Zhang, T., Sakawa, Y., Shoji, T., Nishida, Y., Yugami, N., Downer, M., Fisher, D., Newberger, B., and Tajima, T., "A proof-of-principle experiment of laser wakefield acceleration", Phys. Scripta, T52, $61-64$ (1994); Nakajima, K., Fisher, D., Kawakubo, T., Nakanishi, H., Ogata, A., Kato, Y., Kitagawa, Y., Kodama, R., Mima, K., Shiraga, H., Suzuki, K., Yamakawa, K., Zhang, T., Sakawa, Y., Shoji, T., Nishida, Y., Yugami, N., Downer, and Tajima, "Observation of ultrahigh gradient electron acceleration by a self-modulated intense short laser pulse," Phys. Rev. Lett. 74, 4428-4431 (1995).

[18] Kato, Y., Kitagawa, Y., Tanaka, K. A., Kodama, R., Fujita, H., Kanabe, T., Jitsuno, T., Shiraga, H., Takabe, H., Murakami, M., Nishihara, K., and Mima, K., "Fast Ignition and Related Plasma Physics Issues with High Intensity Lasers," Plasma Phys. Control. Fusion, 39, A145-A151 (1997).

[19] Kodama, R., Norreys, P.A., Mima, K., Dangor, A.E., Evans, R.G., Fujita, H., Kitagawa, Y., Krushelnick, K., Miyakoshi, T., Miyanaga, N., Norimatsu, T., Rose, S.J., Shozaki, T., Shigemori, K., Sunahara, A., Tampo, M., Tanaka, K.A., Toyama, M., Yamanaka, T., and Zepf, M., "Fast heating of ultrahigh-density plasma as a step towards laser fusion ignition," Nature 412, 798-802 (2001).

[20] Rosen, M.D., Hagelstein, P.L., Matthews, D.L., Campbell, E.M., Hazi, A.U., Whitten, B.L., MacGowan, B.J., Turner, R.E., Lee, R.W., Charatis, G., Busch, G.E., Shepard, C.L., and Rockett, P.D., "Exploding-foil technique for achieving a soft x-ray laser," Phys. Rev. Lett. 54, 106-109 (1985).

[21] Lee, T.N., McLean, E.A., and Elton, R.C., "Soft x-ray lasing in neonlike germanium and copper plasmas," Phys. Rev. Lett. 59, 1185-1188 (1987).

[22] MacGowan, B.J., Maxon, S., Hagelstein, P.L., Keane, C.J., London, R.A., Matthews, D.L., Rosen, M.D., Scofield, J.H., and Whelan, D.A., "Demonstration of soft-x-ray amplification in Nickel-like ions," Phys. Rev. Lett. 59, 2157 2160 (1987).

[23] MacGowan, B.J., Maxon, S., Da Silva, L.B., Fields, D.J., Keane, C.J., Matthews, D.L., Osterheld, A.L., Scofield, J.H., Shimkaveg, G, and Stone, G.F., "Demonstration of x-ray amplifier near the carbon edge," Phys. Rev. Lett. 65, 420-423 (1990).

[24] Daido, H., Kato, Y., Murai, K., Yuan, G., Azuma, H., Shiraga, H., Miura, E., Takabe, H., Nakai, S., Lewis, C.L.S., O'Neill D.M., Neely D., and Djaoui A., "Properties of an exploding foil neon-like germanium soft X-ray laser," Laser and Particle Beams 11, 109-117 (1993).

[25] Wang, S., Gu, Y., Zhou, G., Yu, S., Fu, S., Ni, Y., Wu, J., Zhou, Z., Han, G., Tao, Z., Lin, Z., Wang, S., Chen, W., Fan, D., Zhang, G., Sheng, J., Peng, H., Zhang, T., and Shao, Y., "Experimental investigation of high-gain Ne-like Ge soft-x-ray laser by double-massive-target coupling," J. Opt. Soc. Am. B, 9, 360-368 (1992).

[26] Lewis, C.L.S., Neely D., O'Neill D.M., Uhomoibhi, J.O., Key, M.H., Al Hadithi, Y., Tallents, G.J., and Ramsden, S.A., "An injector/amplifier double target configuration for the Ne-like Ge laser scheme," Opt. Comm. 91, 71-76 (1992).

[27] Murai, K., Shiraga, H., Yuan,, G., Daido H., Azuma, H., Miura, E., Kodama, R., Takagi, M., Kanabe, T., Takabe, H., Kato, Y., Neely, D., O'Neill, D.M., and Lewis, C.L.S., "Lasing properties of the $\mathrm{J}=0-1$ and 2-1 lines of a neonlike germanium soft x-ray laser," J. Opt. Soc. Am. B 11, 2287-2297 (1994).

[28] Lunney, J.G., "Waveguiding in soft x-ray laser experiment," App. Phys. Lett. 48, 891-894 (1986). 
[29] Kato, Y., Yamanaka, M., Daido, H., Shiraga, H., Azuma, H., Murai, K., Yuan, G., Miura, E., Kanabe, T., Takagi, M., Nakai, S., Lewis, C.L.S., O’Neill, D.M., Neely, D., Niibe, M., Tsukamoto, N, and Fukuda, Y., "Coherence and double-pass amplification in Ge soft X-ray laser," in [X-Ray Lasers 1992], ed. Fill, E. E., Institute of Physics, Bristol, Conf. Ser. No. 125, 9-16 (1992).

[30] Carillon, A., Chen, H.Z., Dhez, P., Dwivedi, L., Jacoby, J., Jaegle, P., Jamelot, G., Zhang, J., Key, M.H., Kidd, A., Klisnick, A., Kodama, R., Krishnan, J., Lewis, C.L.S., Neely, D., Norreys, P., O' Neill, D., Pert, G.J., Ramsden, S.A., Raucourt, J.P., Tallents, G.J., and Uhomoibhi, J., "Saturated and near-diffraction-limited operation of an XUV laser at 23.6 nm," Phys. Rev. Lett. 68, 2917-2920 (1992).

[31] Kodama, R., Neely, D., Kato, Y., Daido, H., Murai, K., Yuan, G., MacPhee, A.G., and Lewis, C.L.S., "Generation of small divergence soft x-ray laser by plasma wave-guiding with a curved target, Phys. Rev. Lett. 73, 3215-3218 (1994).

[32] Tsukamoto, M., Niibe, M., Watanabe, Y., Miyake, A., Iizuka, T., Fukuda, Y., Kato, Y., Shiraga, H. Daido, H., Murai, K., Lewis, C.L.S., Neely, D., and O'Neill, D.M., "Radiation damage of multilayer mirrors for soft x-ray lasers," Proc. SPIE 1720, 226-236 (1992).

[33] Daido, H., Kodama, R., Murai, K., Yuan, G., Takagi, M., Kato, Y., Choi, I.W., and Nam, C.H., "Significant improvement in efficiency and brightness of the $\mathrm{J}=0-1$ 19.6-nm line of the germanium laser by use of double pulse pumping," Opt. Lett. 20, 61-63 (1995).

[34] Yuan, G., Murai, K., Daido, H., Kodama, R., and Kato, Y., "Two-dimensional beam characteristics of triple-pulse pumping a Ne-like Ge soft x-ray laser at $19.6 \mathrm{~m}$, Phys. Rev. A 52, 4861-4866 (1995).

[35] Murai, K., Yuan, G., Kodama, R., Daido, H., Kato, Y., Niibe, M., Miyake, A., Tsukamoto, M., Fukuda, Y., Neely, D., and MacPhee, A., "Double-pass amplification in Ge soft x-ray laser with a polarizing half-cavity," Jpn. J. Appl. Phys. 33, L600-L603 (1994).

[36] Kawachi, T., Murai, K., Yuan, G., Ninomiya, S., Kodama, R., Daido, H., Kato, Y., and Fujimoto, T., "Observation of polarization of the soft x-ray laser line in neon-like germanium ions," Phys Rev. Lett. 75, 3826-3829 (1995).

[37] Hettrick, M.C., Underwood, J.H., Batson, P.J., and Eckart, M.J., "Resolving power of 35,000 (5 mA) in the extreme ultraviolet employing a grazing incidence spectrometer," Appl. Opt. 27, 200-202 (1988).

[38] Tsunemi, H., Nomoto, S., Hayashida, K., Miyata, E., Murakami, H., Kato, Y., Yuan, G., Murai, K., Kodama, R. and Daido, H., "Application of a newly developed CCD for soft x-ray-laser experiments," Appl. Phys. B 57, 331-336 (1993).

[39] Yuan, G., Kato, Y., Murai, K., Daido, H., and Kodama R., "Measurement of line widths of Ne-like germanium soft x-ray laser in a slab targets," J. Appl. Phys. 78, 3610-3616 (1995).

[40] Daido, H., Shultz, M. S., Murai, K., Kodama, R., Yuan, G., Goto, J., Tanaka, K. A., Kato, Y., Nakai, S., Shinohara, K., Honda, T., Kodama, I., Iwasaki, H., Yoshinobu, T., Tsukamoto, M., Niibe, M., Fukuda, Y., Neely, D., MacPhee, A., and Slark, G., "Subnanosecond In-Line Soft X-Ray Holography Using Germanium Laser in the $20 \mathrm{~nm}$ Wavelength Region," J. X-Ray Science and Technology 5, 105-120 (1995).

[41] Daido, H., Kato, Y., Murai, K., Ninomiya, S., Kodama, R., Yuan, G., Oshikane, Y., Takagi, M., Takabe, H., and Koike, F., "Efficient soft x-ray lasing at 6 to $8 \mathrm{~nm}$ with Ni-like Lanthanide Ions," Phys. Rev. Lett. 75, 1074-1077 (1995).

[42] Daido, H., Ninomiya, S., Imani, T., Kodama, R., Takagi, M., Kato, Y., Murai, K., Zhang, J., You, Y., Gu, Y., "Nickellike soft-x-ray lasing at the wavelength between 14 and 7.9 nm," Opt. Lett. 21, 958-960 (1996).

[43] Kawachi, T., Kado, M., Tanaka, M., Sasaki, A., Hasegawa, N., Kilpio, A. V., Namba, S., Nagashima, K., Lu, P., Takahashi, K., Tang, H., Tai, R., Kishimoto, M., Koike, M., Daido, H, and Kato, Y., "Gain saturation of nickel-like silver and tin x-ray lasers by use of a tabletop pumping laser system," Phys. Rev A 60, 033815/1-7 (2002).

[44] Guanlong, H., Shiji, W., Zunqi, L., Yuan, G., Huajing, T., Guoping, Z., Kato, Y., Daido, H., Sezaki, S., Hirose, S., Yoon, Y., Jitsuno, T., Takagi, Y., Mima, K., Murai, K., and Takenaka, H., Convex Cylindrical Lens Array Line Focusing System, Acta Optica Sinica 19, 713-717 (1999).

[45] Yoon, G. Y., Imani, T., Daido, H., Jitsuno, T., Kato, Y., Nakatsuka, K., Wang, S., Lin, Z., Gu, Y., Tang, H., and Zhang, G., "Enhancement of x-ray lasing due to the wavefront correction of the line-focusing optics with a largeaperture deformable mirror," App. Phys. Lett. 72, 2785-2787 (1998).

[46] Wang, S., Lin, Z., Gu, Y., Huang, G., Tang, H., Ximing, D., Zhang, G., Kato, Y., Daido, H., Imani, T., Sezaki, S., Hirose, S., Yoon, G. Y., Jitsuno, T., Takagi, Y., Mima, K., Murai, K., "Intense nickel-like neodymium X-ray laser at 7.9nm by double-curved slab target with uniform line focusing techniques," Jpn. J. Appl. Phys. 37, L 1234-1237 (1998). 
[47] Sebban, S., Daido, H., Sakaya, N., Kato, Y., Murai, K., Tang, H., Gu, Y., Huang, G., Wang, S., Klisnick, A., Zeitoun, P., Koike, K., and Takenaka, H., "Full characterization of a high gain saturated x-ray laser at 13.9 nm," Phys. Rev. A 61, 43810/1-9 (2000).

[48] Nilsen, J., Li, Y., Lu, P., Moreno, J. C., and Fill, E. E., "Relative merits of using curved targets and the prepulse technique to enhance the output of the neon-like germanium X-ray laser," Opt. Commun. 124, 297-291 (1994).

[49] Daido, H., Ninomiya, S., Imani, T., Okaichi, Y., Takagi, M., Kodama, R., Takabe, H., Kato, Y., Koike, F., Nilsen, J., and Murai, K., "Atomic number scaling of the nickel-like soft X-ray lasers," Int. J. Modern Phys. B 11, 945-990 (1997).

[50] Dekker, C. D., and London, R. A., "Design for a compact Ni-like tungsten x-ray laser," Phys, Rev. A 57, 1395-1399 (1998).

[51] Daido, H., Sebban, S., Sakaya, N., Tohyama, Y., Norimatsu, T., Mima, K., Kato, Y., Wang, S., Gu, Y., Huang, G., Tang, H., Murai, K., Butzbach, R., Uschmann, I., Vollbrecht, M., and Förster, E., "Experimental characterization of short wavelength Ni-like soft x-ray lasing towards the water window," J. Opt. Soc. Am. B 16, 2295-2299 (1999).

[52] Daido, H., Ninomiya, S., Takagi, M., Kato, Y., and Koike, F., "Wavelength measurement of the Ni-like soft x-ray lasing lines and their comparison to the atomic physics calculation," J. Opt. Soc. Am. B 16, 296-300 (1999).

[53] Sebban, S., Daido, H., Sakaya N., Norimatsu, T., Jitsuno, T., Yoon, G-Y., Mima, K., Kato, Y., Wang, S., Gu, Y., Huang, G., Tang, H., Murai, K., Klisnick, A., Zeitoun, Ph., Butzbach, R., Uschmann, I., Vollbrecht, M., Förster, E., Nilsen, J., Zhang, G., Desai, T., Takenaka, H., and Koike, F., "Studies on collisional pumping soft x-ray lasers at ILE," IEEE J. Selected Topics of Quantum Electron. 5, 1460-146 (1999).

[54] Daido, H., Tang, H., Kato, Y., and Murai, K., "Review of collisional excitation neon-like and nickel-like soft x-ray lasers pumped by multiple infrared laser pulses," Compte Rendus, Special Issue on X-Ray Lasers, Serie IV, No.8, 999-1018 (2000).

[55] Daido, H., "Review of soft x-ray laser development (Invited review paper)," Rep. Prog. Phys. 65, 1513-1576 (2002).

[56] Nagata, Y., Midorikawa, K., Kubodera, S., Obara, M., Tashiro, H., Toyoda, K., and Kato, Y., "Production of an Extremely Cold Plasma by Optical-Field Induced Ionization," Phys. Rev. A 51, 1415-1419 (1995).

[57] Kawachi, T. and Kato, Y., "Resonant photo-pumping x-ray laser scheme using intense characteristic x-rays for water-window radiation generation," Phys. Rev. A 84, 063848/1-7 (2011).

[58] Nickles, P.V., Shlyaptsev, V.N., Kalachnikov, M., Schnürer, M., Will, I., and Sandner, W., "Short pulse x-ray laser at $32.6 \mathrm{~nm}$ based on transient gain in Ne-like titanium, Phys. Rev. Lett. 78, 2748-2751 (1997).

[59] Keenan, R., Dunn, J., Patel, P.K., Price, D.F., Smith, R.F., and Shlyaptsev, V.N., "High-repetition-rate grazingincidence pumped x-ray laser operating at $18.9 \mathrm{~nm}$," Phys Rev. Lett. 94, 103901/1-4 (2005).

[60] Tümmler, J., Janulewicz, K.A., Priebe, G., and Nickles, P.V., "10-Hz grazing-incidence pumped Ni-like Mo x-ray laser," Phys. Rev. E 72, 037401/1-4 (2005).

[61] Li, Y., Lu, P., Pretzler, G., and Fill, E.E., "Lasing in neonlike sulphur and silicon," Opt. Commun. 133, 196-200 (1997).

[62] Li, Y. and Nilsen, J., "Scaling laws for electron densities and gain coefficients in low-Z Ne-like lasers," Phys. Scr. 57, 237-241 (1998).

[63] Kato, Y., Nagashima, A., Nagashima, K., Kado, M., Kawachi, T., Tanaka, M., Hasegawa, N., Sukegawa, K., Namba, S., Lu, P., and Sasaki, A., "X-Ray Laser Development at Advanced Photon Research Center," in [X-Ray Lasers 2000], J. Phys. IV (Proceedings) 11 [2], PR2/3-10 (2001).

[64] Kiriyama, H., Pirozhkov, A.S., Nishiuchi, M., Fukuda, Y., Ogura, K., Sagisaka, A., Miyasaka, Y., Mori, M., Sakaki, H., Dover, N.P., Kondo, K., Koga, J.K., Esirkepov, T.Z., Kando, M., and Kondo, K., "High-contrast high-intensity repetitive petawatt laser," Opt. Lett. 43, 2595-2598 (2018).

[65] Tanaka, M., Nishikino, M., Kawachi, T., Hasegawa, N., Kado, M., Kishimoto, M., Nagashima, K., and Kato, Y., "X-ray laser beam with diffraction-limited divergence with two gain media," Opt. Lett. 28, 1680-1682 (2003).

[66] Pirozhkov, A.S., Esirkepov, T.Z., Pikuz, T.A., Faenov, A.Ya., Ogura, K., Hayashi, Y., Kotaki, H ., Ragozin, E.N., Neely, D., Kiriyama, H., Koga, J.K., Fukuda, Y., Sagisaka, A., Nishikino, M., Imazono, T., Hasegawa, N., Kawachi, T., Bolton, P.R., Daido, H., Kato, Y., Kondo, K., Bulanov, S.V., and Kando, M., "Burst intensification by singularity emitting radiation in multi-stream flows," Scient. Rep. 7, 1-10 (2017).

[67] Kando, M., Pirozhkov, A., Kawase, K., Esirkepov, T., Fukuda, Y., Kiriyama, H., Okada, H., Daito, I., Kameshima, T., Hayashi, Y., Kotaki, H., Mori, M., Koga, J., Daido, H., Faenov, A., Pikuz, T., Ma, J., Chen, L., Ragozin, E., Kawachi, T., Kato,T., Tajima, T., and Bulanov, S., "Enhancement of photon number reflected by the relativistic flying mirror," Phys. Rev. Lett. 103, 235003 (2009). 
[68] Nishiuchi, M., Dover, N.P., Hata, M., Sakaki, H., Kondo, K., Lowe, H.F., Miyahara, T., Kiriyama, H., Koga, J.K., Iwata, N., Alkhimova, M.A., Pirozhkov, A.S., Faenov, A.Y. Pikuz, T.A., Sagisaka, A., Watanabe, Y., Kando, M., Kondo, K., Ditter, E.J., Ettlinger, O.C., Hicks, G.S., Najmudin, Z., Ziegler, T., Zeil, K., Schramm, U., and Sentoku, Y., "Dynamics of laser-driven heavy-ion acceleration clarified by ion charge states," Phys. Rev. Research, 2, $033081(2020)$. 